\title{
Adoção do moodle por professores universitários na perspectiva da teoria ator-rede
}

\author{
Adoption of the moodle by university teachers in the actor-network theory \\ perspective
}

\section{Adopción de moodle por profesores universitarios desde la perspectiva de la \\ teoría del actor-red}

\author{
Márcia Melo Bortolato ${ }^{2}$ \\ Dulce Márcia $\mathrm{Cruz}^{3}$
}

\begin{abstract}
Resumo: Muitas Instituições de Ensino Superior vêm adotando o Moodle como apoio ao ensino presencial tendo como referência as práticas pedagógicas da Educação a Distância $(\mathrm{EaD})$. Contudo, como as condições da $\mathrm{EaD}$ diferem das do ensino presencial, os modos de apropriação da inovação também divergem. Para conhecer as condições e em que medida ocorre o processo de adoção do Moodle foi realizado um estudo de caso longitudinal de cinco anos na Universidade Federal de Santa Catarina (UFSC). A pesquisa contou com variados instrumentos (questionários, entrevistas, observação de disciplinas e análise de relatórios institucionais). Mesclando preceitos e metodologias das teorias ator-rede e difusão de inovações conseguiu-se ampliar a visão dos caminhos percorridos pelos actantes e chegar à conclusão que o Moodle vem sendo usado pelos professores adotantes. No entanto, a grande maioria não usa os seus recursos para estender as aprendizagens da sala de aula para antes, durante e depois do encontro presencial.
\end{abstract}

Palavras-chave: Redes sociotécnicas. Teoria ator-rede - ANT. Práticas pedagógicas.

Abstract: Many Higher Education Institutions have been adopting Moodle as a support for face-to-face teaching with reference to the pedagogical practices of Distance Education (DE). However, since the conditions of the DE differ from those of classroom teaching, the modes of appropriation of innovation also diverge. In order to know the conditions and to what extent the process of adoption of Moodle occurs, a longitudinal case study of five years was carried out at the Federal University of Santa Catarina (UFSC). The research had several instruments (questionnaires, interviews, observation of disciplines and analysis of institutional reports). Merging precepts and methodologies of actor-network theories and diffusion of innovations, it was possible to broaden the vision of the paths traveled by the actants and to reach conclusions that Moodle is being used by the teachers who adopted the platform. However, the vast majority do not use their resources to extend classroom learning before, during and after the face-to-face meeting.

Keywords: Sociotechnical networks. Actor-network theory - ANT. Pedagogical practices.

Resumen: Muchas Instituciones de la Enseñanza Superior vienen adoptando Moodle como apoyo a la enseñanza presencial teniendo como referencia las prácticas pedagógicas de la Educación a Distancia (EaD). Sin embargo, como las condiciones de la EaD difieren de las de la enseñanza presencial, los modos de apropiación de la innovación también divergen. Para conocer las condiciones y en qué medida ocurre el proceso de adopción de Moodle se realizó un estudio de caso longitudinal de cinco años en la Universidad Federal de Santa Catarina (UFSC). La investigación contó con variados instrumentos (cuestionarios, entrevistas, observación de disciplinas y análisis de informes institucionales). Al fusionar preceptos y metodologías de las teorías de la red de actores y la difusión de innovaciones, fue posible ampliar la visión de los caminos tomados por los actores y llegar a la conclusión de que Moodle ha sido utilizado por los maestros

\footnotetext{
${ }^{1}$ Submetido em: 01 ago. 2018 - Aceito em: 01 jul. 2019 - Publicado em: 24 dez. 2019

2 Instituto Federal de Educação, Ciência e Tecnologia de Santa Catarina (IFSC) - E-mail: marcia.melo.ead@gmail.com

${ }^{3}$ Universidade Federal de Santa Catarina (UFSC) - E-mail: dulce.marcia@gmail.com
} 
adoptivos. Sin embargo, la gran mayoría no usa sus recursos para extender el aprendizajes de la sala de clase para antes, durante y después del encuentro presencial.

Palabras clave: Redes sociotécnicas. Teoría del actor-red - ANT. Prácticas pedagógicas.

\section{Introdução}

É evidente o crescente processo de difusão das mídias digitais na sociedade brasileira, que vem consumindo novos dispositivos e criando hábitos e práticas virtuais com voracidade. No entanto, no sistema educacional a velocidade é outra. Para incentivar a adoção de inovações, o governo brasileiro criou, nas últimas três décadas, projetos como o "Programa Nacional de Tecnologia Educacional" (ProInfo), "Programa um computador por aluno" (PROUCA), "Programa Banda Larga nas Escolas" (PBLE), ProInfo Integrado, dentre outros, que visavam orientar e formar os educadores para a inclusão das tecnologias digitais nas práticas pedagógicas. Tais iniciativas foram bem sucedidas no sentido de criar uma percepção de que para melhorar o ensino é necessário integrar as mídias à sala de aula. Tanto que, segundo a Pesquisa Internacional sobre Ensino e Aprendizagem (TALIS) (OCDE, 2013), $27 \%$ dos professores no Brasil afirmavam ter necessidade de formação na área das tecnologias educacionais, enquanto na média dos países participantes da pesquisa era de $19 \%$.

\footnotetext{
Essa demanda reflete ao mesmo tempo uma percepção dos professores da necessidade de letramento para se adaptar às mudanças da realidade, mas também serve como termômetro para se perceber a pressão existente na sociedade, seja nas campanhas midiáticas, seja pelo próprio discurso governamental, seja pela procura de culpados pela propalada crise educacional que a cada dia parece avolumar-se em vez de diminuir (TANAKA, 2015, p. 1).
}

Contudo, a adoção de ambientes virtuais vem se destacando tanto na educação a distância como no ensino presencial. Dentre os diversos programas desenvolvidos ou adotados pelas universidades brasileiras, o Moodle tem ocupado um espaço de destaque dentre as mídias digitais mais disseminadas na virtualização da educação superior, por ser uma plataforma virtual que pode ser integrada aos processos educacionais de diferentes formas. Disponibilizado sob a forma de software livre, gratuito, intuitivo, fácil de utilizar e customizar, que pode dar origem tanto à página de um único professor/formador como à de uma universidade com dezenas de milhares de alunos/utilizadores.

O Moodle (Modular Object Oriented Distance Learning) é um programa desenvolvido por uma comunidade mundial de desenvolvedores. No Brasil, se popularizou principalmente por ser adotado pela Universidade Aberta do Brasil (UAB), desde seu início em 2007, como um sistema (ou plataforma) de gerenciamento para criação de cursos online/a distância. Gradativamente, também vem sendo adotado como apoio ao ensino presencial de universidades integrantes ou não do consórcio $\mathrm{UAB}$, como repositório de materiais didáticos ou como um ambiente virtual de ensino e aprendizagem (AVEA). Quando planejado como repositório, o Moodle permite disponibilizar conteúdos, avisos e algum recurso para ajuda no estilo tutorial. Quando pensado como um AVEA, deve ter por objetivo a construção de conhecimento apoiado por interações promovidas por professores e alunos, dar acesso aos 
conteúdos didáticos, atividades de aprendizagem e abertura de espaços de discussão:

Um AVEA permite que o professor disponibilize antecipadamente os materiais didáticos, possibilitando a extensão das discussões, produções e aprendizagens da sala de aula para antes, durante e depois do encontro presencial. Além disso, democratiza a participação, já que todos, em igualdade de condições, podem se manifestar no AVEA com suas reflexões ou dúvidas, sem precisar disputar a atenção em um momento limitado do encontro presencial (BORTOLATO, 2016).

Utilizado como AVEA, na educação a distância (EaD), o Moodle tem revelado inúmeras possibilidades de práticas pedagógicas inovadoras, com a disponibilização de materiais midiáticos, processos de comunicação síncronos e assíncronos eficazes, possibilidades de trabalhos colaborativos entre estudantes com auxílio do professor apoiando a construção coletiva de conhecimento. Tais práticas da $\mathrm{EaD}$ vêm sendo referências exitosas para o ensino presencial (MANO; CRUZ, 2016) e têm sido objeto de pesquisas sobre seus efeitos no processo de ensino-aprendizagem com foco nos alunos, nos professores e até no próprio desempenho do dispositivo técnico, ou seja, a própria plataforma. No entanto, na análise das pesquisas realizadas sobre essa temática, percebeu-se a frustração dos pesquisadores no fato de que as experiências desenvolvidas na $\mathrm{EaD}$ não conseguem ser replicadas no ensino presencial.

Na pesquisa feita com professoras da Universidade Federal de Santa Catarina, Martins (2012) concluiu que elas utilizavam o Moodle como uma plataforma gerenciadora de arquivos, priorizando o armazenamento de conteúdos e a organização do trabalho docente e não como espaço virtual para as práticas formativas e pedagógicas. Segundo Alves e Brito (2005, p. 9),

Discutir a presença dos elementos tecnológicos na sociedade contemporânea se
constitui em condição sine-qua-non. Pensá-los como elementos mediadores do fazer
pedagógico é o nosso grande desafio, já que a interação com estes suportes deve se
constituir em condição básica para o processo de formação de docentes seja no
nível inicial ou continuado, contribuindo assim, para uma melhora significativa da
práxis pedagógica destes professores.

A alegada inadequação e desconhecimento do professor é parte do processo de adoção de inovação sobre o qual incidem inúmeros fatores. Dentre esses fatores, pode-se citar as diferenças do perfil dos professores com relação ao uso das mídias digitais em sua vida social e em sua atuação profissional; disponibilidade e qualidade dos processos de formação de cada instituição; conhecimentos específicos com relação aos recursos do Moodle; disponibilidade e incentivos para utilizar seu tempo de trabalho e até seu tempo social ${ }^{i}$ para desenvolver tarefas virtuais, dentre outros. Neste sentido, a adoção do Moodle traria desafios para a universidade ao implicar num processo de inovação não só com potencial para modificar rotinas, práticas e estruturas que não tinham sido criadas para abrigar as características e demandas da modalidade semipresencial, mas, principalmente, a cultura docente do ensino presencial.

Por essa complexidade, o processo de inovação utilizando o Moodle no ensino presencial ainda não é totalmente compreendido. Em especial, como vem se dando nas práticas pedagógicas a partir da percepção dos professores adotantes. Neste sentido, algumas 
questões podem ser levantadas: quem são e o que pensam os diversos envolvidos no processo dentro da instituição educacional? O que se pode saber da inovação estudando o que os professores dizem e o que fazem em suas ações inovadoras?

Neste contexto, o objetivo principal desta pesquisa foi investigar se existia uma rede sociotécnica para a difusão da inovação Moodle no ensino presencial e como criar estratégias que permitissem acompanhá-la e descrevê-la em seus elementos atuantes. Também interessava saber se a adoção do Moodle no ensino presencial teria inovado as práticas pedagógicas, como os professores vivenciavam as possíveis mudanças e quais suas ações relacionadas à inovação. Para alcançar esses objetivos, foi realizada uma pesquisa de doutorado (BORTOLATO, 2016) na Universidade Federal de Santa Catarina (UFSC), que buscou revelar os fluxos, as controvérsias, as estratégias eficazes e ineficazes do processo de adoção do Moodle no ensino presencial. O estudo de diferentes momentos e enfoques durante cinco anos resultou numa grande quantidade de dados qualitativos e quantitativos. A opção teórico-metodológica para dar conta de analisar a complexidade desses dados foi mesclar alguns aspectos da teoria da difusão de inovações (Diffusion of Innovations Theory - DIT), com a perspectiva da análise sociotécnica com base na teoria Ator-Rede (Actor-network Theory - ANT).

A justificativa para essa abordagem consiste em que ela permite investigar o fenômeno da inovação representada pelo Moodle na educação presencial a partir dos rastros deixados pelos professores investigados e suas percepções sobre o processo vivenciado. Com isso, as teorias DIT e ANT puderam ser utilizadas de forma complementar (apesar de suas diferenças) para tentar ampliar a visão do pesquisador sobre o objeto de estudo, se afastando dos trabalhos de levantamento etnográfico e dando espaço para que o objeto dirigisse o processo de investigação sobre ele próprio.

De acordo com Pinto e Domenico (2014, p. 4, grifos do original), a abordagem preconizada pela ANT pede ao pesquisador que entoe "um 'mantra latouriano' de 'seguir os atores"”. E foi assim, entoando o mantra latouriano, que seguimos os rastros deixados pelos professores, nossos actantes investigados, em sua relação com o Moodle, outro actante acompanhado. A partir de suas indicações fomos aqui e acolá, indo e voltando nos fluxos da rede, seguindo seus passos como formigas na construção do formigueiro.

Apresenta-se a seguir uma síntese dos fundamentos teórico-metodológicos da ANT e DIT e o que delas foi recortado para uso na presente pesquisa.

\section{As teorias ANT e DIT}

A Actor-Network Theory (ANT), de Latour (2012) possibilita pesquisar "objetos" na perspectiva de redes, observando seus fluxos e sua dinâmica de construção e desconstrução. Entende que não existe um único centro, mas "nós" que vão criando novas malhas e ampliando a rede. Nela, tem-se os mediadores que desempenham papel atuante para recrutar aliados, por meio de traduções que influenciam as decisões e coexistem na busca de informações. De suas ações resulta a formação de grupos sociais que sustentam a rede pela 
integração de mais e mais intermediários - os que transportam significados sem transformálos.

De acordo com Latour (2012, p. 55), para delinear um grupo, criá-lo do nada ou simplesmente restaurá-lo, é preciso dispor de porta-vozes que "falem pela existência do grupo". Portanto, uma forma de localizar os grupos é identificar seus porta-vozes. Todos os elementos da rede (humanos e não humanos) são considerados actantes e definidos a partir de suas ações, em determinado momento, como mediadores ou intermediários.

Segundo as palavras de Latour (2001, p. 91): “conhecer não é apenas explorar, mas conseguir refazer os próprios passos, seguindo a trilha demarcada". Para isso, Pedro (2008) sugere quatro passos básicos para a observação: (1) buscar uma porta de entrada; (2) identificar os porta-vozes; (3) acessar os dispositivos de inscrição; e, (4) mapear as ligações da rede. Na perspectiva da ANT a observação deve ser detalhada, sem pressa, atenta a qualquer detalhe. Nunca sobre um objeto estático. São os movimentos que trouxeram o objeto até sua configuração atual, ou seja, o que importa são os fluxos, as negociações, seguir o que foi traçado e jamais traçar para seguir.

A segunda teoria que embasou a pesquisa foi a Diffusion of Innovations Theory (DIT), de Rogers (2003), para o qual uma inovação é primeiramente adotada por um grupo pequeno de pessoas que são os Inovadores (2,5\% do universo investigado), mais dispostos a correr riscos. Depois vêm os Adotantes precoces (12,5\%), que muitas vezes fazem parte do círculo social dos inovadores e são informados da inovação por estes. Os dois grupos adotam as inovações rapidamente. São muito importantes para que o processo de inovação se difunda, são considerados formadores de opinião. A seguir, estão os adotantes potenciais (34\%), que só adotam a inovação após um grau variável de tempo, raramente ocupam cargos de liderança de opinião em um sistema. A Maioria cética ou tardia (34\%) aguarda a inovação ser amplamente testada, antes de se arriscar a utilizá-la. E, por fim, temos os Retardatários (16\%), que são muito relutantes em mudar, normalmente tendem a se concentrar em "tradições", sendo que alguns nunca chegam a adotá-la.

Para a DIT, a adoção de inovações acontece como um processo de cinco fases: (1) conhecimento; (2) persuasão; (3) decisão; (4) implementação; e, (5) confirmação. O usuário da inovação pode abandonar o processo em qualquer fase. O poder de persuasão de líderes de opinião e de agentes de mudança influencia consideravelmente a taxa de adesão.

A partir destas duas visões, observou-se os fluxos construídos na instituição UFSC pelos professores para a adoção do Moodle em suas práticas pedagógicas, buscando identificar mediadores, intermediários, porta-vozes, e, também, os inovadores, adotantes precoces e retardatários. Mediadores, intermediários e porta-vozes são conceitos de classificação de personagens dentro da Teoria Ator-rede (ANT) e, inovadores, adotantes precoces e retardatários fazem parte da Teoria da Difusão de Inovações (DIT). Analisou-se a natureza dos grupos, das ações, dos objetos e dos fatos, assim como as etapas do processo de adoção e as características das inovações percebidas pelos indivíduos que influenciam na sua decisão. 


\section{A adoção do moodle na UFSC}

O Moodle é utilizado na UFSC, desde 2007, em programas de EaD. Em 2009 foi disponibilizado para os cursos presenciais. O Moodle UFSC opera de forma síncrona com os sistemas acadêmicos, de forma que o cadastramento de disciplinas, turmas, professores e estudantes é realizado automaticamente com base nos dados contidos nestes sistemas. Durante o semestre pode ser utilizado livremente e, ao final, as notas gerenciadas no Moodle UFSC são transpostas para os sistemas acadêmicos.

O crescimento quantitativo do uso do Moodle no presencial na UFSC pode ser verificado pelo número de turmas registradas no Centro Acadêmico de Graduação (CAGr), com professores que utilizaram o Moodle (indo de 58\% em 2012/1, a 71\% em 2016/1). O CAGr centraliza informações sobre a graduação, quantidade de turmas, de alunos, sistema de notas, aprovação e reprovação. Mas, os dados de utilização são insuficientes para se entender o modo como vem sendo adotado, ou seja, quais práticas pedagógicas o Moodle tem estimulado e quais trilhas foram seguidas pelos professores em seus processos de adoção da inovação.

Latour (2012) usa uma metáfora de formigas e trilhas de formigas para se referir aos actantes e as marcas deixadas por suas ações durante o processo de construção da rede. $\mathrm{O}$ autor faz um jogo de palavras porque sua proposta de Actor-network Theory resulta na sigla ANT, que significa 'formiga' na língua inglesa. Copiando a metáfora ANT de Latour, foram seguidas as trilhas das formigas para ver de onde vêm, quantas são, o que fazem pelo caminho, a quais grupos pertencem, o que buscam e o que querem mostrar. Para visualizar detalhes da trilha das formigas nos cinco anos de investigação, aplicaram-se questionários com professores e coordenadores de cursos, procedeu-se com a análise do Moodle de algumas disciplinas, foram entrevistados professores, analisados dados dos processos de formação docente do Programa de Formação Continuada para Professores (PROFOR) da UFSC e das ações desenvolvidas pela Superintendência de Tecnologia de Informação e Comunicação (SeTIC) que influenciaram a formação da rede sociotécnica estudada. Aqui serão descritos e analisados alguns desses dados.

\section{Seguindo os rastros: a formação dos grupos}

A coleta de dados teve início com a observação dos rastros deixados no sistema tecnológico da Instituição de 2012 a 2013, onde se encontrou o destaque de uso de alguns professores, "formigas" que pisaram mais forte sobressaindo entre as demais. Foi elaborado um questionário com 37 perguntas enviado para 434 professores, recebendo um retorno de 75, de diferentes Centros Acadêmicos. A estratégia principal para a elaboração e análise dos dados do questionário foi identificar grupos na perspectiva da ANT e da DIT. Cada categoria de perguntas levou à diferenciação de perfis e as respostas possibilitaram concomitantemente a inclusão em grupos distintos, conforme apresenta-se na sequência. 
Latour (2012) recomenda que, antes de criar grupos e investigar os actantes, deve-se considerar que um ator pode ser enquadrado num deles e, às vezes, em mais de um grupo. Actantes entram e saem de grupos, então seguir rastros pode evidenciar tais situações. Trabalhando nesta perspectiva, foram criadas categorias de análise dos actantes para definir alguns agrupamentos (seguindo a orientação de Latour: o segredo é definir o ator com base naquilo que ele faz - seus desempenhos) e poder comparar as ações dos grupos, verificar semelhanças e diferenças entre eles, ou seja, as controvérsias ${ }^{\mathrm{ii}}$.

Os primeiros grupos criados para análise na pesquisa foram EaD versus Presencial, para distinguir os membros que já tinham atuado na $\mathrm{EaD}$ e os que não tinham essa experiência. No contraponto entre os dois grupos foram avaliados os conhecimentos sobre o Moodle, participação em formação específica para uso da plataforma, as opiniões em relação à formação que participaram e onde buscam conhecimentos ou ajuda para o uso: na perspectiva da ANT os fluxos, influências, traduções, mediadores, intermediários, agentes de mudanças, líderes de opinião. Não foi identificada grande diferença entre os dois grupos com relação aos seus conhecimentos de Moodle, nem na busca de conhecimentos.

Verificou-se uma distinção considerável com relação aos cursos de formação: a maioria do grupo EaD declarou buscar nas formações algo mais instrumental, pragmático e objetivo enquanto o grupo Presencial buscava algo mais extenso com questões teóricas e planejamentos didáticos. Pode-se entender tais diferenças ao pensar que o grupo que tem experiência em EaD já possuía algum conhecimento de como desenvolver didaticamente as atividades virtuais, desejando para sua evolução conhecer mais ferramentas e recursos disponíveis; já o grupo presencial, sem experiência com o Moodle, desejava primeiramente o conhecimento básico instrumental e, depois, como utilizar tais recursos de forma didática, ansiando assim, por cursos de formação mais longos que possibilitassem tal evolução.

Novos grupos comparativos foram criados, com seus membros definidos a partir do tempo que utilizavam o computador diariamente, os Plugados (que acessavam mais de oito horas por dia), Conectados (de seis a oito horas) e Ligados (de duas a cinco horas). Nesta nova formação de grupos, foram verificadas as respostas relacionadas aos consumos pessoais de mídia, o significado da Internet na vida de cada um e o grau de dificuldade em fazer algumas tarefas básicas na web - lembrando que, na perspectiva da DIT, buscava-se inovadores, adotantes precoces, potenciais, tardios ou retardatários. Apesar de encontrado um grupo que ficava no computador duas horas por dia e outro mais de oito horas, não houve diferenças significativas entre os consumos pessoais de um para o outro. Sendo assim, não foi possível distinguir pelos dados desta formação de grupos quem eram os inovadores, adotantes precoces, potenciais, tardios ou retardatários.

Por essa razão, foram definidos novos grupos, categorizados como Autodidatas (que buscavam conhecimentos apenas em tutoriais), Parceiros (buscavam conhecimentos apenas com outros professores), Sem-fontes (não buscam conhecimentos sobre o Moodle em nenhumas das opções apresentadas) e os Multi-fontes (que tiveram formação na Instituição e também bebem em outras fontes). Na comparação entre estes grupos foram analisadas a frequência dos usos pedagógicos de algumas mídias, quais estratégias e recursos que utilizavam em aula presencial e as dificuldades identificadas para adotar o Moodle como um 
AVEA. Foi também considerado o nível de conhecimento de cada recurso disponível na plataforma Moodle, analisado os estágios de adoção segundo a DIT: conhecimento; persuasão; decisão; implementação ou confirmação. Neste viés, algumas distinções foram observadas entre os grupos, por exemplo: Parceiros e Multi-fontes declararam ter conhecimentos básicos do Moodle, enquanto Sem-fontes e Autodidatas se julgavam experientes. Já na questão ligada ao conhecimento de cada recurso disponível na plataforma, os Sem-fontes não confirmavam ser experientes, pois diziam que não usavam vários dos recursos apresentados por acharem complicados.

Na perspectiva da DIT entende-se que Parceiros e Multi-fontes estavam na fase do conhecimento e/ou persuasão. Se olhar-se para esta configuração pela perspectiva da TAR vê-se estes dois grupos como intermediários (os que transportam significados sem transformá-los, que são influenciados por mediadores), que desempenham papel atuante para recrutar aliados, por meio de traduções que influenciam as decisões e coexistem na busca de informações.

\section{Análise dos agrupamentos}

Alguns resultados valem ser comentados de forma mais detalhada a partir das análises dos grupos. Percebeu-se que a maioria dos professores tinha bom domínio de mídias na vida pessoal, usava com frequência e sem dificuldades quase todos os recursos apresentados, e, apesar disso, para a grande maioria $(99,5 \%)$ dos professores, a principal estratégia didática eram as aulas expositivas e os recursos, o PowerPoint (88\%) e o texto (75\%), independentemente de seu grupo.

Alguns se destacavam no uso das mídias, tanto na vida pessoal como no uso didático, mas foram poucos: apenas quatro de 75 professores que se descreveram como expertos em Moodle.

Não foram identificados com clareza e confiança, nessa primeira parte dos estudos, quem eram os mediadores, os intermediários, tampouco os líderes de opinião ou agentes de mudança, apesar de seguir-se várias trilhas e analisar-se os diversos agrupamentos. Identificou-se alguns fluxos e traduções que permeavam o processo de adoção, como a troca de conhecimento entre professores, declarada por 35\% dos entrevistados e a contribuição dos processos de formação para utilizar a plataforma, declarada por $30 \%$ dos professores entrevistados. Poderíamos dizer que no grupo de professores que trocavam informação havia líderes de opinião ou mediadores, que transmitiam as informações e influenciavam nas decisões de adoção. Da mesma maneira, no processo de formação teríamos agentes de mudança, mas seria uma conclusão precipitada e sem evidências suficientes.

A verdade é que seguir as trilhas de grupos foi importante para ter uma visão global dos perfis, mas não identificou as tramas e conexões de forma explícita e confiante. Então foram selecionados alguns professores que apresentaram o perfil de mais uso de recursos do Moodle e solicitada permissão para visualizar o AVEA de sua disciplina. Dos 20 professores solicitados, 12 autorizaram. Os AVEAs das disciplinas foram analisados a partir de alguns 
critérios e, dentre os analisados, entrevistou-se cinco professores, cada um de um Centro Acadêmico diferente, para conhecer tais actantes bem de perto na busca de descobrir mais informações. Nesta nova amostra foram cruzados os dados do perfil construído a partir das respostas do questionário, análise do AVEA e as falas de cada entrevista pessoal.

Apesar de a amostra ser bem reduzida, menor que $10 \%$ da primeira, foi considerada significativa, ao se contemplar o olhar em foco, conforme recomenda a ANT, desvelando questões não percebidas anteriormente, tais como a diferença na configuração da rede de um Centro Acadêmico para outro. Para Latour (2012), a ANT se considera mais capaz de vislumbrar ordem depois de deixar os atores desdobrarem o leque inteiro de controvérsias nas quais se meteram. É como se fosse dito aos atores: "Não vamos tentar disciplinar vocês, enquadrá-los em nossas categorias; deixaremos que se atenham aos seus próprios mundos e só então pediremos sua explicação sobre o modo que os estabeleceram" (LATOUR, 2012, p. 44).

Nas falas analisadas apareceram diferentes configurações dentro da rede sociotécnica. Em alguns Centros Acadêmicos, a dinâmica se configurava estruturada com mediadores ativos e a tradução acontecia (na perspectiva da ANT). Na perspectiva da DIT, percebeu-se que o processo de difusão era desenvolvido por um grupo de inovadores e adotantes precoces. Percebeu-se Centros Acadêmicos agindo como atores da rede, considerando que "uma rede de atores é simultaneamente um ator, cuja atividade consiste em trazer novos elementos para dentro de sua rede, redefinindo-a e transformando-a constantemente" (CARVALHO, 2007, p. 48). Em outros centros, a transformação (adoção da inovação) acontecia de maneira lenta, sem a ação ativa de mediadores, apresentando um processo lento, ou seguindo a curva de "S" da DITii, estando ainda na segunda etapa, apesar de já ter iniciado havia cinco anos.

Conforme Rogers (2003, p. 15), “muitas inovações exigem um longo período de tempo, muitas vezes de muitos anos, a partir do momento que se tornam disponíveis até o momento em que são amplamente adotadas". Observou-se algumas controvérsias como a de um ator que se declarou como experto em Moodle, mas nunca fez um curso. Outra controvérsia foi de um professor que, mesmo estando em um contexto muito propício, já que fazia parte do grupo de formação de professores, não evidenciava uma ação de mediador, de agente de mudança ou líder de opinião.

Esta fase de pesquisa resultou importante, pois foram percebidas associações e processos de negociações que ocorrem antes que um coletivo seja constituído pelo objeto/fato/característica que o define como comum de uma coletividade, tão ou mais importante que o resultado final. Em outras palavras, "quanto mais nos aproximamos, mais as coisas se tornam controversas" (LATOUR, 2000, p. 53).

Para completar a visão do percurso voltamos à SeTIC para atualizar os dados coletados em 2013 e confirmar algumas questões percebidas no percurso de 2012 até 2016. Primeiramente, foi acessado o relatório de adoção do Moodle por professores, em cada semestre, do período 2012/1 a 2016/2, por Campi. Nessa análise ficou evidente que a adoção do Moodle nos campi novos (Araranguá, Blumenau, Joinville, Curitibanos) era muito maior do que no Central e que, além disso, nestes lugares, os poucos casos de professores que não 
estavam usando o Moodle no presencial aconteciam apenas no primeiro semestre de sua atuação. Tais dados foram confirmados em outro relatório, o de turmas de Moodle em relação às turmas criadas no CAGr. O aumento da adoção de Moodle era proporcional ao aumento de turmas do Centro Acadêmico, demonstrando o processo de adoção mais acelerado de todos os Centros Acadêmicos.

Confirmava-se assim, a existência de uma rede sociotécnica bem estruturada, com mediadores traduzindo rápida e eficazmente a inovação adotada para todo novo membro do campus. O processo foi instaurado fortemente no início das atividades de tais campi, por meio de porta-vozes ou líderes de opinião, "um tipo de liderança informal, capaz de influenciar as atitudes dos outros indivíduos ou comportamentos" (ROGERS, 2003, p. 388). Conclui-se que a coesão dessas redes pode ter ocorrido pelas condições propícias encontradas, de pouca resistência ao uso de artefatos tecnológicos, por dois motivos: surgirem numa época em que a Cultura Digital já estava proeminente na sociedade; e, serem campi que têm acentuada atuação nas áreas de tecnologia e engenharias.

Ao verificar como estava ocorrendo a evolução do processo de adoção do Moodle no presencial da UFSC (de todos os Centros) foi constatado que, apesar da evolução se apresentar constantemente crescente, os índices de adesão (média de $62 \%$ nos cinco anos investigados) eram muito inferiores aos encontrados nos campi novos (96\%). A título de comparação, verificou-se a evolução do processo de adoção no centro que teve a mais baixa adesão de professores (Centro de Ciências Jurídicas), confirmando-se que também estava aumentando, pois apesar de ter índices baixos (10\% em 2012 e 17\% em 2016), cresceu em $7 \%$ no período estudado. O mesmo apareceu em centros intermediários no processo de adoção, como o Centro de Física e Matemática que cresceu 8\% (48\% em 2012 para 56\% em 2016) e o Centro de Filosofia e Ciências Humanas que cresceu $16 \%$ neste período ( $40 \%$ para $56 \%)$.

\section{Análise dos não humanos}

Como a pesquisa teve como inspiração a ANT, não seria possível desconsiderar os possíveis actantes não humanos da rede. Conforme Latour (2012), o papel de cada ator é definido a partir do seu desempenho neste universo, ou seja, o quão ativo e repercussivo é, quanto efeito produz na sua rede. Sendo assim, fez-se necessário analisar o papel da Instituição UFSC na rede, por meio de seus gestores, os coordenadores de curso, bem como a SeTIC, e o PROFOR. A SeTIC, por ser a responsável técnica pelo Moodle UFSC, em todas as suas aplicabilidades e o PROFOR, por se constituir como agente da Instituição responsável pela capacitação dos professores para uso do Moodle.

Por meio das respostas ao questionário, os coordenadores do curso que participaram da amostra se distinguiram em dois grupos de perfis. Oito coordenadores podem ser considerados como intermediários e dois se configuravam como mediadores. Os intermediários consideravam que as dificuldades, encontradas pelos professores do seu curso, para uma maior utilização de recursos digitais na sala de aula, se dava pela falta de 
conhecimento sobre as possibilidades de uso dos recursos digitais. Os mediadores declararam que as formações promovidas para os professores foram iniciativas exclusivas do departamento e/ou da coordenação. Todos os coordenadores consideravam que a alta taxa de efetivação do Moodle no presencial se devia ao interesse do próprio professor e não por conta de exigência da instituição; por conta do interesse e solicitação dos alunos (50\%) e, por incentivo de alguns professores inovadores que partilhavam com os colegas suas descobertas e satisfação com tal uso (40\%).

Portanto, segundo essa análise, não poderia ser caracterizada uma ação de forte persuasão da Instituição na representação de seus coordenadores. Eles (80\%) viam o Moodle como uma ferramenta virtual que poderia ser utilizada como apoio ao ensino presencial. Declararam (80\%) que no seu curso existia uma forte utilização da plataforma como repositório de conteúdo, para postagem dos textos trabalhados na sala de aula. O fato de dois coordenadores serem considerados como mediadores se deve mais por chefiar departamentos que promoviam cursos de formação para seus professores, e menos por sua ação direta de persuasão. Foram observados Centros que tinham uma rede bem estruturada e um processo crescente de adoção do Moodle no ensino presencial, sendo que, em um desses, quase 100\% dos professores usavam o Moodle e, pela narrativa do professor entrevistado, deste Centro, percebeu-se a influência dos mediadores e líderes de opinião.

Outro actante encontrado na rede foi a SeTIC, responsável técnica pelo Moodle UFSC, em todas as suas aplicabilidades (EaD, Presencial, Extensão) e também pelo desenvolvimento de tutoriais disponíveis na plataforma e atualização de novas versões. A SeTIC dava suporte para usuários, com um $F A Q$ de perguntas e respostas frequentes organizado por temas gerais, perguntas de alunos e de professores, bem como um sistema de chamado online para dúvidas e atendimento técnico, alimentando um banco de dados sobre os usos do Moodle na UFSC e gerando diversos relatórios de acompanhamento para a Instituição e pesquisadores, que muito auxiliou nesta pesquisa.

Actante importante na rede, pela geração da inovação nesse universo de pesquisa, muitas de suas ações eram voltadas à tradução (tutoriais), na perspectiva da ANT, mas também poderia ser considerada como um agente de mudança, ao influenciar a taxa de adesão, na perspectiva da DIT, já que muitos usuários poderiam desistir do uso se não tivessem informações e ajuda imediata disponível em poucos cliques direto no Moodle UFSC. Por isso, pode-se percebê-la como um agente mediador, dentro da rede sociotécnica.

O PROFOR era o agente da Instituição responsável pela capacitação dos professores para uso do Moodle. Para a ATN, uma rede de atores é simultaneamente um ator, cuja atividade consiste em trazer novos elementos para dentro de sua rede, redefinindo-a e transformando-a constantemente. Sendo assim, pode-se considerar o PROFOR como um actante na rede, um ator não humano. Os ministrantes dos cursos, agindo em nome da Instituição/PROFOR, compartilhavam seus conhecimentos e, ao mesmo tempo, envolviam e mobilizavam aliados para a rede. Conforme Latour (2012, p. 55), "para delinear um grupo, quer seja necessário criá-lo do nada ou simplesmente restaurá-lo, cumpre dispor de portavozes que falem pela existência do grupo" e o PROFOR "foi" o porta-voz com seus 
ministrantes de curso (ou agentes de mudança e líderes de opinião, na perspectiva da DIT). Os cursos de capacitação para uso do Moodle promoviam a tradução.

A presença do PROFOR na rede foi muito significativa, principalmente no início da disponibilização do Moodle para o presencial, tanto que, nos três primeiros anos (2009-2011), foram desenvolvidas 54 formações. No entanto, os não humanos, "pela própria natureza de seus laços com os humanos, logo deixam de ser mediadores para se transformarem em intermediários" (LATOUR, 2012, p. 109). Isso pode justificar a diminuição da formação nos últimos três anos da pesquisa (2014-2016), em que foram ofertados apenas oito cursos com foco no uso do Moodle. Assim, o PROFOR deixou de ser um mediador para assumir o papel de intermediário.

\section{Comentários finais}

Nesta pesquisa, entende-se, à luz das teorias, que a rede sociotécnica formada para a adoção da inovação Moodle, no ensino presencial da UFSC, teve particularidades em cada Centro Acadêmico. Alguns Centros tiveram a importante figura do tradutor (porta-vozes, mediadores, agentes de mudanças ou líderes de opinião) e, assim, o processo de difusão da inovação se deu de forma acelerada e se configurou no momento final da pesquisa, em fase de fechamento da caixa preta, "estabilização ou solidificação" de uma situação (na perspectiva da ANT), ou na última fase da "curva de S" (na perspectiva da DIT), já que atingiram a quase totalidade de membros adotantes da inovação estudada.

Outros Centros apresentaram um processo de adoção lento, porém, constante, mas que pareceu ser muito mais pela demanda da Cultura Digital do que pela influência interna de mediadores ou agentes de mudança. Também não pode-se desconsiderar que o processo de inovação, nos Centros mais antigos e tradicionais da UFSC, enfrentou barreiras resistentes, tais como o enraizamento de um ensino tradicional perpetuado em mais de meio século de existência.

Observou-se na trajetória da pesquisa, como o Moodle veio sendo adotado pelos professores. Comprovou-se que a situação revelada em pesquisas anteriores permaneceu igual até o momento final desta pesquisa. Os professores da UFSC que utilizavam o Moodle no ensino presencial, em grande maioria, independente de pertencer a um Centro tradicional ou a um Centro novo, não atingiram os requisitos necessários para caracterizá-lo como um AVEA.

Os relatórios de Centros e o geral da UFSC apresentavam como recursos mais utilizados a postagem de arquivos e como atividades a entrega de tarefas e os fóruns. Mesmo parecendo uma incongruência, os fóruns não podem ser considerados como um recurso de discussão pois, automaticamente, todas as disciplinas têm um fórum de notícias, exclusivo para avisos do professor (comunicação unidirecional), que não pode ser excluído e que foram contabilizados nos dados do relatório, por isso, esse dado não é tão animador. 
O objetivo da pesquisa, que buscava responder a pergunta: se existia uma rede sociotécnica para a difusão da inovação Moodle no ensino presencial da UFSC, foi respondido afirmativamente, pois conseguiu-se identificá-la.

A pergunta seguinte: se a adoção do Moodle no ensino presencial teria inovado as práticas pedagógicas e, em caso afirmativo, de que maneira os professores vivenciavam tal mudança, teve como resposta que as inovações não eram tantas como presumia-se, já que a maioria dos professores usava o Moodle mais para apoio logístico para entrega e envio de avisos. Observou-se poucos casos em que desenvolveram atividades de ensino-aprendizagem, configuradas como AVEA. Mas, também encontrou-se alguns inovadores, apresentando estratégias assertivas, podendo, com seu exemplo, se transformarem em agentes de mudanças. Percebeu-se que os poucos que transformaram o Moodle em AVEA e, com isso, inovaram suas práticas pedagógicas, aceitaram a mudança de forma muito otimista e animadora, ressaltando em suas falas as vantagens percebidas.

Para a questão sobre o que os professores precisavam para inovar, a pesquisa mostrou que há necessidade de tradutores. Os tradutores (mediadores, porta-vozes, líderes de opinião, agentes de mudança) já atuavam no contexto estudado, porém, o que pareceu faltar foram os canais de comunicação, que, segundo a DIT, são um elemento-chave para a difusão de inovação acontecer. Os canais de comunicação poderiam ser criados de forma estratégica, em reuniões pedagógicas, momentos de formação, planejamentos didáticos entre outros, ou seja, com as possibilidades de fluxos para as informações que estavam sendo criadas por alguns dos inovadores. Nesse sentido, apenas conseguiu-se identificar o trabalho do PROFOR, por meio das estratégias de formação.

Finalmente, este artigo buscou expor o potencial da associação das teorias ANT e DIT para análise de grande quantidade de dados em pesquisas com foco na difusão de inovações. Os resultados apontaram uma simetria entre sucesso e fracasso do processo de difusão de inovações, devendo ser considerado relevante e, portanto, digno de ser investigado em suas minúcias, em conjunto com a perspectiva de redes sociotécnicas, tanto para o desenvolvimento, como para o encerramento do investimento em determinada inovação.

\section{Referências}

ALVES, Lynn Rosalina Gama; BRITO, Mário Sérgio da Silva. O Ambiente Moodle como Apoio ao Ensino Presencial. In: $\mathbf{1 2}^{\circ}$ Congresso Internacional de Educação a Distância. Florianópolis, 2005.

BORTOLATO, Márcia Melo. Inovação e práticas pedagógicas: o moodle no ensino presencial da Universidade Federal de Santa Catarina. 2016. 290 f. Tese (Doutorado em Educação) - Universidade Federal de Santa Catarina, Florianópolis, 2016.

CARVALHO Ingrid Aline de. A rede sociotécnica na formação de professores de ciências da natureza, matemática e suas tecnologias/física. 2007. 169 f. Dissertação (Mestrado em Educação Científica e Tecnológica) - Universidade Federal de Santa Catarina, Florianópolis, 2007. 
KENSKI, Vani Moreira. Tecnologias e Tempo Docente. 1 ed. São Paulo: Papiru, 2013.

LATOUR, Bruno. A Esperança de Pandora. Bauru, SP: EDUSC, 2001.

LATOUR, Bruno. Ciência em ação: como seguir cientistas e engenheiros sociedade afora. São Paulo: Editora UNESP, 2000.

LATOUR, Bruno. Reagregando o Social. Uma introdução à teoria do ator-rede. Salvador: EDUFBA, 2012; Bauru: EDUSC, 2012.

MANO, Marina Lemos Carcereri; CRUZ, Dulce Márcia. As práticas e linguagens da cultura digital na educação: uso do Moodle e letramento midiático de professores de uma universidade pública. RENOTE - Revista Novas Tecnologias na Educação. Porto Alegre, v. 14, n. 1, p. 1-10, jul. 2016.

MARTINS, Aline Santana. Um olhar sobre as mídias em práticas pedagógicas na didática universitária. 2012. 194 f. Dissertação (Mestrado em Educação) - Programa de Pós-Graduação em Educação, Universidade Federal de Santa Catarina, Florianópolis, 2012.

NOBRE, Júlio Cesar de Almeida; PEDRO, Rosa Maria Leite Ribeiro. Reflexões sobre possibilidades metodológicas da Teoria Ator-Rede. Cadernos UniFOA. Volta Redonda, n. 14, p. 47-56, dez. 2010.

OCDE. Organização para Cooperação e Desenvolvimento Econômico. Pesquisa Internacional sobre Ensino e Aprendizagem (TALIS). OCDE: França, 2013.

PEDRO, Rosa Maria Leite Ribeiro. Redes e Controvérsias: ferramentas para uma cartografia da dinâmica psicossocial. In: VII ESOCITE - Jornadas Latino-Americanas de Estudos Sociais das Ciências e das Tecnologias. Rio de Janeiro, 2008. Anais... Rio de Janeiro, 2008.

PINTO, Clovis Cerretto; DOMENICO, Silvia Marcia Russi de. Teoria ator-rede em estudos organizacionais: encontrando caminhos via cartografia de controvérsias. In: VIII Encontro de Estudos Organizacionais da ANPAD. Gramado, RS, 2014.

ROGERS, Everett. Diffusion of innovations. New York: Free Press, 2003.

TANAKA, Eliane. Professor: as dificuldades para utilizar a tecnologia dentro da sala de aula das escolas públicas brasileiras. NIC.br - Núcleo de Informação e Coordenação do Ponto BR. 29 jul. 2015.

\section{Notas}

i Conforme Kenski (2013), o tempo de trabalho docente são as horas contratadas e pagas pela instituição educacional em que atua. O tempo social inclui as horas que atua em casa, no seu tempo livre, que deixa de ser utilizado para o convívio social em prol do atendimento de alunos no AVEA.

ii $\mathrm{O}$ termo controvérsia refere-se a uma disputa em que se alegam razões pró ou contra, nas quais se podem evidenciar movimentos cujo desdobramento será a consecução de um objetivo comum (NOBRE; PEDRO, 2010). 
iii Segundo estudos de Rogers (2003, p. 23), o resultado da análise do comportamento dos adotantes é explicitado na taxa de adoção, que é "a velocidade relativa com o qual uma inovação é adotada por membros de um sistema social". A adoção tem um padrão médio de tempo para cada adotante que pode ser representado por uma curva em forma de "S". 